\title{
Adesão e não-adesão à terapia anti-retroviral: as duas faces de uma mesma vivência
}

\author{
Adhesion and non adhesion to anti-retroviral therapy: the two faces of a same experience \\ Adhesión y no adhesión a la terapia antiretroviral: las dos caras de una misma vivencia
}

\author{
Ana Lúcia Cardoso Nogueira da Silva', Maria Angélica Pagliarini Waidman', Sônia Silva Marcon' \\ 'Universidade Estadual de Maringá. Maringá. PR
}

Submissão: $19 / 03 / 2008$

Aprovação: $11 / 02 / 2009$

\section{RESUMO}

O objetivo do estudo foi compreender, a partir da perspectiva de portadores e familiares, os aspectos que influenciam na adesão à terapêutica anti-retroviral. Trata-se de um estudo descritivo, de natureza Qualitativa, desenvolvido no período de junho de 2006 a julho de 2007, junto a 10 indivíduos portadores do HIV/Aids, acompanhados pelo Serviço de Atendimento Especializado em Aids de Campo Mourão - PR e seus familiares. Constituem fatores facilitadores da adesão: adoção de estratégias para lembrar horários e mascarar o gosto do medicamento, ausência de efeitos colaterais, número reduzido de medicamentos a serem ingeridos e capacidade para reconhecê-los, lembrança dos sintomas da doença e o apoio da rede social. A ausência destes fatores pode culminar na não-adesão.

Descritores: Enfermagem; Síndrome de Imunodeficiência Adeuirida; Anti-retrovirais.

\begin{abstract}
The objective of the study was to understand, from the perspective of HIV bearers and family, the aspects that influence in the adhesion to the antiretroviral therapy. It is a descriptive study, of Qualitative nature, carried out from June 2006 to July 2007, with 10 HIV/Aids positive individuals, attended at the Service of Specialized Care on Aids of Campo Mourão - PR and their relatives. The considered facilitative factors of the adhesion are: adoption of strategies to remind schedules and to mask the taste of the medicine, absence of side effects, reduced number of medicines to be taken and capacity to recognize them, memory of the symptoms of the disease and the support of the social group. The absence of these factors can culminate in non adhesion.
\end{abstract}

Descriptors: Nursing; Acquired Immunodeficiency Syndrome; Anti-retroviral agents.

\section{RESUMEN}

El objetivo del estudio fue comprender, a partir de la perspectiva de portadores y familiares, los aspectos Que influyen en la adhesión a la terapéutica antiretroviral. Se trata de un estudio descriptivo, de naturaleza cualitativa, desarrollado en el período de junio de 2006 a julio de 2007, junto a 10 individuos portadores del VIH/SIDA, acompañados por el Servicio de Atención Especializado en SIDA de Campo Mourão PR y sus familiares. Constituyen factores Que facilitan la adhesión: adopción de estrategias para recordar horarios y enmascarar el sabor del medicamento, ausencia de efectos colaterales, número reducido de medicamentos a ser ingeridos y capacidad para reconocerlos, recuerdo de los síntomas de la enfermedad y el apoyo de la red social. La ausencia de estos factores puede culminar en la no-adhesión.

Descritores: Enfermería; Síndrome de Inmunodeficiencia Adeuirida; Agentes antirretrovirales. 


\section{INTRODUÇÃO}

A adesão ao esquema terapêutico anti-retroviral (ARV) é ao mesmo tempo um dos maiores desafios para o sucesso do tratamento do HIV/Aids e a mais poderosa arma contra a Aids. Essa terapêutica tem produzido resultados muito positivos, representados pelo prolongamento da vida e melhoria de sua Qualidade $^{(1)}$, diminuição de episódios mórbidos e do número e freqüência de internações. Em contrapartida, para que estes benefícios sejam observados se faz necessária uma boa adesão à terapia por parte dos usuários ${ }^{(2)}$.

A eficácia do tratamento está atrelada a um processo dinâmico, interativo e contínuo, Que envolve os profissionais de saúde e o indivíduo com Aids ${ }^{(2,3)}$ e é influenciado por fatores relacionados à síndrome, ao tratamento, à personalidade do indivíduo, à equipe de saúde, à rede social e outros ${ }^{(3)}$.

No caso específico do Brasil, a introdução da terapia antiretroviral, associada à oferta gratuita dos medicamentos nos serviços de saúde pública e à modificação dos critérios de definição de caso, tem permitido melhor expectativa e melhor Qualidade de vida aos portadores de HIV/Aids ${ }^{(4,5)}$. Para isso, entretanto, o acesso ao tratamento deve ser facilitado, o Que não significa apenas disponibilizar os medicamentos, mas principalmente, junto com o portador e a família, estabelecer um plano terapêutico Que possa ser seguido, considerando-se que a adesão refere-se à habilidade do portador em seguir as prescrições e recomendações a ele propostas, entendendo os benefícios que o tratamento pode trazerIhe ${ }^{(6)}$.

Apesar de existirem várias definições acerca de adesão e aderência ao tratamento ARV, optamos por aQuela Que se reporta à adesão como a conduta do indivíduo ao seguir as prescrições médicas, Quanto à posologia, à Quantidade de medicamentos por horário, ao tempo de tratamento e às recomendações especiais para determinados medicamentos. A não-adesão aos ARVs, por sua vez, tem sido relacionada basicamente a Quatro grupos de fatores: a pessoa em tratamento, a doença, o serviço de saúde e o apoio social $^{(7)}$. Assim, ao se discutir a adesão e não-adesão aos ARVs, é necessário ressaltar Que a Aids é uma doença crônica, sem cura conhecida até os dias atuais, e Que, por isso mesmo, o indivíduo precisa fazer uso constante de medicação, como forma de prolongar a vida com Qualidade ${ }^{(8)}$. Desta forma, percebendo a importância do tema para a enfermagem no sentido de oferecer um cuidado integralizado, desenvolveu-se um estudo que buscou compreender os aspectos Que influenciam pacientes com Aids e seus familiares na adesão e não-adesão à terapêutica anti-retroviral ${ }^{(9)}$.

\section{MÉTODO}

Trata-se de um estudo de natureza Qualitativa, realizado no Serviço de Ambulatório Especializado (SAE) em Aids em uma cidade do interior do Estado do Paraná. Foram informantes do estudo 20 indivíduos, sendo 10 pessoas vivendo com HIV/Aids e seus respectivos cuidadores familiares, Que compareceram no ambulatório no período destinado à coleta de dados. Esta se deu em dois momentos: o primeiro em junho de 2006 e o segundo em abril de 2007. Utilizamos como técnicas a consulta a documentos e entrevistas. Os documentos examinados foram os prontuários dos pacientes no SAE, onde foram coletadas informações referentes à história epidemiológica e à evolução do paciente no serviço. As entrevistas, do tipo semi-estruturadas, foram realizadas individualmente no domicílio com os portadores e os respectivos cuidadores. Foram utilizados três instrumentos: um roteiro do tipo planilha, para o registro dos dados coletados dos prontuários, e dois roteiros de entrevista, um para o portador e um para o cuidador. Estes instrumentos foram elaborados pelas pesquisadoras com base nos objetivos do estudo.

A técnica de análise foi a temática ${ }^{(10)}$ Que utiliza a freeüência das unidades de significação como definidoras do caráter do discurso, ou então, no aspecto Qualificativo, a presença de determinados temas como valores de referência, e ainda os modelos de comportamento presentes no discurso.

O desenvolvimento do estudo seguiu os preceitos éticos disciplinados pela Resolução n. ${ }^{\circ}$ 1 96/96 do Conselho Nacional de Saúde e o projeto foi aprovado pelo Comitê Permanente de Ética em Pesquisa da Universidade Estadual de Maringá (Parecer 208/ 2006). Todos os participantes assinaram o Termo de Consentimento Livre e Esclarecido em duas vias. Na apresentação dos resultados, os depoentes estão identificados por cores e seus familiares pela mesma cor acrescida da letra $\mathrm{C}$.

\section{RESULTADOS E DISCUSSÃO}

Os usuários foram sete homens e três mulheres, dos Quais sete eram casados (inclusive as três mulheres), dois conviviam na condição de união consensual e um era divorciado (Quadro 1). Suas idades variaram de 28 a 60 anos (média de 40 anos). Os dados epidemiológicos referentes à Aids no Brasil revelam que a forma de transmissão mais freQüente do HIV/Aids é a atividade sexual, com maior ocorrência na faixa etária adulta ${ }^{(4,5)}$.

Nota-se ainda neste Quadro Que a maioria dos portadores continuou trabalhando e provendo às despesas da casa, o Que nos leva a refletir sobre a importância da evolução e eficácia da terapêutica ARV atual, a Qual permite ao paciente trabalhar e manter sua família. É importante salientar a ausência de analfabetos, visto Que um nível maior de escolaridade favorece a compreensão sobre a patologia e terapêutica medicamentosa, o que é relevante para a adesão ao tratamento. A baixa escolaridade dos indivíduos infectados com o HIV/Aids encontrada também tem sido sistematicamente identificada em outros trabalhos ${ }^{(4,5)}$. A precária inserção escolar e a escassez de recursos financeiros dos portadores de HIV/Aids demonstram mudança no perfil da epidemia, uma vez Que inicialmente a Aids era mais freqüente entre indivíduos do sexo masculino, com melhor poder aquisitivo e maior escolaridade ${ }^{(1)}$.

\section{A adesão à terapêutica anti-retroviral}

$\mathrm{O}$ uso de medicamentos e a adesão ao tratamento ARV foram descritos pelos portadores de formas diferenciadas, sendo que alguns demonstraram comprometimento desde o início do tratamento.

\section{[...] Quando descobri, estava só, então aprendi a me virar sozinho} (Rosa).

Outros, no entanto, demonstraram ter precisado de um tempo para se adaptar e aceitar o uso dos medicamentos ARV: 


\begin{tabular}{|l|l|l|l|l|l|}
\hline Cor & Sexo & Estado civil & Idade & Profissão & Escolaridade \\
\hline Amarelo & $\mathrm{M}$ & Casado & 44 & Policial Militar & Ensino médio \\
\hline Rosa & $\mathrm{F}$ & Casado & 30 & Vendedora & Ensino médio \\
\hline Laranja & $\mathrm{M}$ & União consensual & 28 & Técnico em eletrônica & Ensino médio \\
\hline Lilás & $\mathrm{F}$ & Casado & 30 & Do lar & Ensino fundamental \\
\hline Branco & $\mathrm{M}$ & Casado & 60 & Motorista & Ensino fundamental \\
\hline Azul & $\mathrm{M}$ & Casado & 53 & Motorista & Ensino fundamental \\
\hline Verde & $\mathrm{M}$ & Casado & 41 & Mecânico & Ensino fundamental \\
\hline Vermelho & $\mathrm{F}$ & Casado & 39 & Escrituraria & Ensino médio \\
\hline Marrom & $\mathrm{M}$ & Divorciado & 45 & Açougueiro & Ensino fundamental \\
\hline Cinza & $\mathrm{M}$ & União consensual & 34 & Pedreiro & Ensino fundamental \\
\hline
\end{tabular}

\section{Quadro 1. Dados sociodemográficos dos portadores de HIV/Aids, 2007.}

[...] antes eu sofria mais para tomar o remédio, eu não aceitava; agora caiu a ficha, sei que tenho que tomar o remédio (Laranja).

No exemplo abaixo podemos observar eue Azul precisou de apoio e estímulo dos profissionais, revelando Quão importante é uma atuação eficaz dos profissionais no início do tratamento, especialmente porque a boa adesão nesse período pode significar adesão em longo prazo ${ }^{(1)}$

No começo da terapia eu precisava de suporte; é muito difícil, Quando se está doente. Para aderir à medicação, tem Que ter vontade. Fui orientado dos efeitos colaterais e estimulado (Azul).

Observamos também Que o estado de saúde no momento do diagnóstico parece interferir na aceitação da nova realidade; ademais, parece Que os sujeitos, Quando estão mais debilitados, tornam-se mais resistentes e temerosos, o Que pode dificultar a realização do autocuidado, demonstrando a necessidade de apoio intenso por parte da equipe.

Quando comecei a medicação eu estava muito fraca e internada, então a enfermeira é Quem me dava a medicação; mas Quando fui para casa, já conseguia tomar sozinha (Rosa).

A não-aceitação da condição de portador de uma doença estigmatizante por certo interfere na aderência a seu tratamento. Nestes casos, mais uma vez a atuação dos profissionais de saúde e da rede social se mostra imprescindível para estimular o indivíduo, mesmo Que no início ele demonstre aderência a partir de uma obrigação, como ocorre com Laranja. Percebe-se Que a história dos aderentes é uma história de superação de dificuldades, relacionadas não apenas às características complexas dos esQuemas medicamentosos, mas também àQuelas referentes ao estilo de vida e ao estigma da doença ${ }^{(7)}$.

É interessante observar Que a polaridade de alguns fatores pode atuar como determinante positivo ou negativo da adesão, dependendo das circunstâncias e do momento em Que eles se manifestem. Por exemplo, o fato de serem apoiados em excesso ou o de não serem apoiados pelos familiares podem tanto estimular Quanto desestimular a adesão. Assim, ao serem abordados em referência à adesão ao tratamento $\mathrm{ARV}$, a maioria dos portadores de HIV/Aids assim relata seu comportamento:

\section{[...] faço o tratamento com total seriedade, tenho todo o apoio Que preciso (Lilás).}

Não obstante, a nossa prática profissional tem revelado outra realidade, a Qual também começou a ser desvelada até mesmo entre os dez portadores em estudo: no decorrer da entrevista, mesmo aqueles que no início afirmaram tomar corretamente os medicamentos, revelaram Que na prática cotidiana não era bem assim:

Tem um que eu tenho que tomar ao dormir, mas eu não agüento; vou tentar tomar dia sim, dia não, mas eu sei Que não vou agüentar Nerde).

A baixa adesão constitui uma grande preocupação. Estudos identificaram elevado índice de não-adesão (em torno de 30\%), sendo que, nos casos de uso dos anti-retrovirais a taxa de aderência exigida é de $100 \%$, e ela inclui não simplesmente o uso, mas o uso regular, pois se isto não ocorre, pode haver falência no tratamento, possibilitando o aparecimento de novas cepas virais resistentes e comprometendo o prognóstico do indivíduo ${ }^{(7.11)}$.

Observa-se Que, apesar de os propósitos do serviço incluírem o estabelecimento do plano terapêutico junto com o portador e a família, estes não parecem ter sido suficientemente sensibilizados sobre a importância da regularidade do horário, e por esta razão adotam estratégias Que associam a ingestão dos ARVs a outras atividades já pertencentes à sua rotina de vida - como dormir, acordar, fazer as refeições, entre outras, as Quais por sua natureza não têm como ponto central a regularidade no horário.

Ao acordar e ao dormir, se eu durmo até tarde, eu tomo tarde, se eu acordo cedo, eu tomo cedo, mesmo sabendo que o horário tem que ser certinho (Laranja).

Eu não controlo, tomo na hora do café e na janta (Branco).

A problemática da não-adesão é exacerbada Quando, além dos 
sintomas, a pessoa tem medo da possibilidade de outros virem a saber do diagnóstico em decorrência de sofrer alguns efeitos colaterais:

Quando começou a medicação foi difícil, tinha sintomas, não Queria Que ninguém soubesse; mas agora está mais fácil, tem menos medo (Rosa C).

Outra Questão bastante referida pelos portadores é o medo do desconhecido - no caso, a doença - ou até de ter que tomar remédio até o fim da vida ${ }^{(12)}$. Isto pode prejudicar o tratamento, mesmo Quando esse portador tem uma cuidadora comprometida e sabedora da necessidade de se manter regularidade nos horários, como observado no caso de Marrom:

Eu dou o medicamento na hora que ele levanta às seis da manhã, mas tem dia que ele levanta às 10 da manhã, tudo depende. À noite, ele toma às 10 da noite. Tem Que comer junto, se não ele não toma (Marrom C).

É interessante observar Que os portadores relatam ter adotado algumas estratégias Que os ajudem a manter a regularidade do tratamento, procurando em alguns casos estabelecer uma rotina:

Não sinto dificuldade, raramente eu esqueço a medicação; eu acostumei, tem um lugar certo (Lilás).

Em alguns esQuemas anti-retrovirais se exige Que o medicamento seja ingerido em jejum, a fim de promover a sua absorção. Mesmo considerando o desconforto dessa ação, identificou-se que, ao fazer uso de uma rotina, o portador tomava adequadamente os medicamentos prescritos.

Como são vários comprimidos, separo os Que têm Que ser tomado em jejum, e tomo os demais de uma só vez, os Que precisam estar de estômago cheio, todos também (Azul).

Com relação a este aspecto, considera-se o trabalho do enfermeiro fundamental na orientação e acompanhamento do paciente para Que ele adira ao tratamento, e isso foi ressaltado por um dos entrevistados:

Sei que todos esses medicamentos precisam de orientação para poder tomar. Falta de conhecimento dos efeitos colaterais, da dieta de cada medicação, sem tal apoio, o portador se assusta, toma remédio irregular (Azul).

Consideramos de suma importância o portador ser acompanhado desde o primeiro mês, devido à possibilidade de surgir um grande número de reações e efeitos colaterais. Além do mais, o acompanhamento do profissional de saúde pode minimizar as conseqüências do impacto da doença e da não-adesão aos medicamentos $A R V^{(6)}$.

\section{Fatores facilitadores da adesão}

Dentre os fatores Que facilitam a adesão ao tratamento, sem dúvida nenhuma, o principal é a ausência de efeitos colaterais dos medicamentos. Também é valorizada a Quantidade de medicamentos a serem ingeridos:

Eu considero fácil, porque eu só tomo três comprimidos por dia. Não passo mal e não tenho enjôo (Lilás).

São igualmente valorizados os esquemas terapêuticos adotados representados pelo número de vezes em Que os medicamentos devem ser ingeridos ao longo do dia.

O horário, porQue são só duas vezes ao dia... (Rosa C).

A Quantidade de medicamentos ingeridos diariamente interfere na adesão em decorrência da maior probabilidade de efeitos colaterais, além da dificuldade de ingestão ${ }^{(6)}$. A complexidade do tratamento e o número de doses e de drogas contribuem para a não-adesão(5) ${ }^{(5)}$, sendo Que para cada comprimido ingerido o risco da não-adesão aumenta em $12 \%{ }^{(8)}$.

Outro aspecto Que favorece a adesão aos medicamentos antiretrovirais é a presença de uma memória dos sintomas da doença. Os portadores costumam referir Que não Querem passar pelo Que já passaram anteriormente, Quando estavam sintomáticos, e por isto tentam seguir corretamente o tratamento:

Eu tomo para não ter sintomas, porQue Quando fieuei doente, fieuei amarelo, não conseguia trabalhar, Quase morri (Laranja).

Assim, mesmo nos casos em Que os pacientes, numa atitude de fuga e negação, afirmam não Querer obter maiores informações sobre a doença e seu tratamento; a memória da experiência vivenciada anteriormente lhes permite saber o mínimo necessário, ou seja, Que sem o tratamento as suas chances são pequenas. Nestes casos, aderem ao tratamento proposto por obrigação ou por medo da morte:

Não conheço sobre o tratamento, e não Quero conhecer, só sei Que Quase morri, e agora preciso tomar esse remédio para não morrer (Branco).

Em um estudo realizado no Interior Paulista com indivíduos com HIV/Aids, identificou-se Que 14\% dos portadores, Quando Questionados sobre os fatores Que facilitam a adesão à terapêutica ARV, referiram o desaparecimento dos sintomas da doença. O mesmo também foi verificado neste estudo, uma vez Que, sem sintomas, o portador pode retornar à sua vida normal, sem conseqüências para a vida social, e Que a Aids é, na atualidade, uma doença crônica com a Qual todos podem conviver, desde Que haja a adesão adeQuada à terapêutica anti-retroviral ${ }^{(2)}$.

É interessante observar Que essa memória relacionada com a fase sintomática da doença também é referida pelos cuidadores, Que manifestam a preocupação em não deixar Que seu familiar interrompa o tratamento:

Sei Que se ele parar ele vai piorar e voltar a ficar doente de novo, ele vai ficar com quadros dificultosos (Marrom C).

Às vezes um cuidado simples, como ingerir algum tipo de alimento específico após a ingestão do medicamento, ou até mesmo 
embrulhá-lo em alguma substância para mascarar o cheiro e a aparência, atua como facilitador de adesão:

[...] o horário facilita, e poder tomar café depois, senão eu não conseguiria tomar. Mesmo assim, eu já tive que cobrir as cápsulas com chocolate, pois eu não conseguia. (Laranja).

A conscientização sobre a gravidade da doença e a importância do tratamento ARV e de suas características também constitui um fator importante para a adesão:

Sei Que se perder esse medicamento vai Queimar uma etapa, e não posso diminuir minha imunidade; então tento arduamente tomar corretamente meu medicamento (Rosa).

Com relação a este aspecto, é importante esclarecer Que, no início do tratamento, portador e família são incentivados e orientados para o uso correto da terapêutica ARV, principalmente para evitar falha terapêutica, visto Que melhores resultados desta terapêutica ocorrem com o primeiro e segundo esquemas, enquanto os subseqüentes são menos eficazes ${ }^{(1)}$.

Quando Questionados sobre como é o esquema de tratamento e como são os medicamentos utilizados, vários portadores, apesar de demonstrarem familiaridade com o esquema terapêutico, revelaram reconhecer os medicamentos a serem ingeridos em cada horário de acordo com as características dos comprimidos, tais como o tamanho, a cor, a Quantidade e o número impresso, demonstrando não ter dificuldades nesse aspecto.

Cedo eu tomo três vermelhos de geladeira, e à noite também; e tem um tipo aquela sulfa, branquinho, na hora que eu janto e acordo. O nome eu não sei, já falei Que eu não lembro nome (Verde).

Embora a memorização dos nomes dos medicamentos constitua um recurso importante para assegurar seu uso correto, a maioria das mulheres de um estudo realizado no Ceará não sabia informar a medicação prescrita. Tal levou os autores a considerar Que isto talvez ocorra em função da complexidade e diversidade dos nomes dos ARVs, Que dificultam sua assimilação(11).

Alguns portadores, no entanto, sabem o nome dos medicamentos Que fazem parte de seu esquema terapêutico; alguns sabem inclusive o nome comercial e o nome da composição, além de saberem informar a dosagem utilizada:

O Biovir é branco e Atazanavir é azul, eu tomo de 200mg, porque eu engordei (Rosa).

Outros portadores conseguem relacionar os efeitos colaterais de cada um dos medicamentos utilizados. No relato de Azul, por exemplo, além deste aspecto, é possível perceber também Quanto é difícil para o portador conviver com todos os efeitos colaterais e a importância de se poder contar com a ajuda de familiares e até de profissionais, especialmente no início do tratamento.

No início da terapia, precisa de muito apoio da família e de psicólogo, pois causa delírio; depois normaliza (Azul).

\section{Rede social como elemento motivador na adesão ao ARV}

Observou-se Que os indivíduos Que apresentavam melhor aderência ao tratamento eram aQueles Que possuíam uma rede social, ou seja, Que referiam procurar colegas de igreja ou o marido para ajudar na resolução dos problemas, enQuanto os não-aderentes não pertenciam a nenhum grupo social. Em relação à Aids, alguns autores consideram Que a participação em grupos de apoio estimula a adesão ao tratamento ${ }^{(3,11)}$.

Uma rede social pessoal estável, sensível, ativa e confiável protege a pessoa na vida cotidiana, atua como agente de ajuda e encaminhamento, interfere na construção e manutenção da autoestima, acelera os processos de cura e recuperação, aumenta a sobrevida - enfim, é geradora de saúde tanto nos aspectos físicos e mentais como nos psicológicos e afetivo-emocionais ${ }^{(13)}$.

Desde o nascimento até a morte, o ser humano participa de uma trama interpessoal Que o molda e ao mesmo tempo contribui para moldar a sua rede social. De início, essa trama é constituída pela família, mas em pouco tempo se expande e passa a incluir os amigos, colegas de estudo e trabalho, além de relações baseadas em atividades sociais, culturais, esportivas, de culto e de cuidados de saúde ${ }^{(13)}$.

Quando comecei a medicação, eu estava muito fraca e internada, então a enfermeira é Quem me dava a medicação; mas Quando fui para casa, já conseguia tomar sozinha (não podia contar com a ajuda da família, pois ela não sabia do diagnósticol(Rosa).

Em nossa prática já havíamos observado Que Rosa, Que não pode contar sua condição de portadora de HIV/Aids nem mesmo para a sogra, com Quem mora, com freeüência passava horas no ambulatório conversando com outros pacientes, revelando a falta Que sentia de poder conversar livremente sobre a doença com outras pessoas. Cada vez Que observávamos a atitude de Rosa no ambulatório pensávamos sobre a importância da rede social como apoio para os indivíduos portadores desta e de tantas outras patologias, em especial as estigmatizantes.

As redes podem ser entendidas como um sistema composto por vários objetos sociais, ou seja, pessoas, funções e situações Que oferecem apoio instrumental e emocional à pessoa, em suas diferentes necessidades. Apoio instrumental é entendido como a ajuda financeira e na divisão de responsabilidades em geral, e informação prestada ao indivíduo. Apoio emocional, por sua vez, refere-se à afeição, aprovação, simpatia e preocupação com o outro e, também, a ações Que levam a um sentimento de pertencer ao grupo. Os suportes sociais recebidos e percebidos pelas pessoas são fundamentais para a manutenção da saúde mental, para o enfrentamento de situações estressantes - como cuidar de alguém doente por muito tempo - e também para o alívio do estresse físico e mental e para a promoção da saúde e do bem-estar ${ }^{(13)}$.

Podemos inferir Que viver com Aids é uma condição cada vez mais comum, na medida em Que os avanços médicos e sociais vãona transformando em uma doença crônica. A adesão ao tratamento medicamentoso ARV tem contribuído para isso. Viver com uma doença crônico-degenerativa é um desafio, por isso a comunidade científica e a rede social estão unidas para proporcionar qualidade de vida aos portadores e combater o preconceito, o estigma e a discriminação arraigados no viver com Aids ${ }^{(3)}$.

$\mathrm{O}$ paciente refere outro agravante no Que diz respeito à rede de 
suporte social. Quando ele se imagina portador do HIV, a falta de informação faz com Que ele passe por uma fase de isolamento social, por opção ou por exclusão da comunidade, diminuindo assim as possibilidades de apoio e ajuda. Os dois atores sociais envolvidos nessa pesquisa - portadores e cuidadores - sofreram um forte impacto social e emocional ao se depararem com o diagnóstico. Após essa fase, apegam-se à fé religiosa e à esperança de cura.

\section{[...], mas eu acredito muito em Deus, e vai dar tudo certo (Azul C).}

Vários estudos têm apontado Que a religião constitui um importante apoio para a família e o portador no enfrentamento da doença $^{(14,15)}$. A religião/espiritualidade tem papel importante na manutenção e recuperação da saúde dos membros familiares, uma vez Que a fé e a esperança podem ajudar a aliviar a dor e o sofrimento da família causados pela presença da doença no cotidiano, além de serem motivo de esperança em relação à cura ${ }^{(15)}$.

Observamos também Que, conforme identificado em outros estudos, é comum portadores acometidos de uma doença grave mudarem de religião ou mesmo se tornarem assíduos freeüentadores ${ }^{(14,15)}$ :

\section{[...] do contrário não encontraria forças para lutar. Participo agora da Igreja Evangélica (Amarelo).}

Isto ocorre, provavelmente, por dois motivos: o primeiro é Que os portadores sentem necessidade de uma maior aproximação com rituais religiosos, pois estes são carregados de sentimentos de esperança, além de proporcionarem uma paz interior Que eles não são capazes de encontrar de outra forma; e o segundo é Que, especialmente nos casos de doenças estigmatizantes como a Aids, os portadores parecem sentir necessidade de seguir uma religião Que seja mais rigorosa, pois necessitam de estratégias Que lhes possibilitem aliviar a culpa Que sentem por terem adQuirido esta doença, Que ainda não é aceita pela sociedade.

Em um estudo com mulheres portadoras do HIV/Aids foi observado ao longo das entrevistas Que elas conhecem a condição a Aids de doença incurável e buscam apoio religioso para amenizar o sofrimento diante da infecção ${ }^{(16)}$. Este apoio é considerado um dos recursos mais utilizados por elas para conseguirem viver e enfrentar a doença e também para amenizar situações de estresse decorrentes da Aids ${ }^{(17)}$.

Por fim um dos aspectos observados como favorecedor da adesão ao tratamento foi a preocupação com os filhos, a Qual leva os portadores a assumir com responsabilidade o tratamento. Observase Que esta preocupação está presente mesmo entre aQueles pais Que não conseguem abolir todos os vícios.

Assim, mesmo sem conseguir parar de fumar e saber do risco de adoecer, o instinto da paternidade atua como facilitador da adesão:

Como eu falei, não parei de fumar, e não consigo parar.Sou magro, como bem, durmo bem, tenho as crianças para cuidar (Branco).

\section{Fatores dificultadores da adesão ao tratamento ARV}

Por outro lado, foram identificados como aspectos Que dificultam a adesão ao medicamento anti-retroviral, entre outros, a Quantidade de medicamentos a ser ingerida, pois a complexidade do tratamento desfavorece a adesão a ele.

O Que dificulta é Quando ele está longe de mim. Se ele vai para a casa do meu irmão ele não toma. No começo ele não aceitava, e eu tinha que colocar na comida, no suco; agora ele engole o comprimido, mas tem que dar na boca. Ele toma vários outros medicamentos por dia: Quatro psiquiátricos, um do diabetes e um do colesterol. Pelo menos agora ele não precisa mais de vitaminas (Marrom C).

Este, contudo, não é um fator determinante para todos os entrevistados, uma vez Que Branco também ingere vários comprimidos ao longo do dia e ainda assim apresenta uma boa aderência ao esquema terapêutico proposto.

Na verdade, eu tomo um monte de remédio... Para pressão, para diabetes, eu tomo 23 comprimidos por dia, cada hora é um... Os de Aids, eu sei porque é quando eu acordo e Quando eu durmo, nunca carrego ele no bolso.Eu não sinto nada de diferente, só as náuseas (Branco).

Os cuidados necessários com alguns medicamentos - como, por exemplo, a necessidade de mantê-los sob refrigeração - também são alguns dos fatores apontados como dificultadores da adesão, uma vez Que nem todos os portadores contam com este aparelho em seu domicílio. Além disso, Quando há necessidade de levar o medicamento para o trabalho, nem sempre é possível utilizar um refrigerador de uso comum sem que outras pessoas fiquem sabendo do diagnóstico.

O que dificulta muito é Quando eu trabalho. O remédio de geladeira, ele fica borrachudo, eu não consigo tomar. Eu trabalho em fazendas, fica longe e por vários dias, eu não tenho onde deixar [...] (Verde).

O medo do preconceito no local de trabalho constitui um fator importante de não-adesão ao tratamento de forma correta. Destarte, parece existir uma associação direta entre o fator trabalho e a nãoadesão ao medicamento $A R V$, gerando um impacto negativo na participação do cliente em seu tratamento. Verifica-se assim Que o medo do preconceito e da discriminação ultrapassa a fronteira da família, tornando-se presente no ambiente de trabalho, associado ao sentimento de viva inQuietação ante a noção do perigo real ou imaginário da ameaça, do temor de perder o emprego, visto Que este significa possibilidade de independência econômica, de sua contribuição na renda familiar e satisfação das necessidades básicas da família ${ }^{(18)}$.

Outro fator bastante relevante da não-adesão ao tratamento ARV é o surgimento de efeitos colaterais

No começo eu tinha náuseas, e às vezes eu tenho náuseas. Será Que é por causa do remédio? [...] eu não sinto nada de diferente, só as náuseas (Branco).

O suporte oferecido por profissionais em relação ao tratamento, representado por apoio, informações adeQuadas sobre o tratamento 
e esclarecimentos sobre a gravidade dos efeitos colaterais, pode aumentar a adesão( ${ }^{(1)}$.

A não-observação de resultados positivos, associada à necessidade de troca da medicação, também representa um fator Que dificulta a adesão, pois sempre Que se troca a medicação o portador tende a conviver com uma fase de adaptação à nova terapêutica, a Qual Quase sempre é acompanhada de efeitos colaterais e mudanças na rotina.

O mais complicado são os efeitos colaterais, na troca de medicamentos. Passou muito mal, ficou muito triste. Acho que tem que ter um apoio psicológico muito grande, todo dia ficar insistindo que a vida é boa, Que vale a pena. Não é fácil lembrar de tudo o que passou. Ele quase morreu. Então para mim o maior problema foi a troca de medicamento. Não sei por Que ele teve que trocar. (Cinza C)

A troca de esquema terapêutico se faz necessária Quando o portador não responde ao tratamento, o Que é observado por aumento da carga viral na corrente sangüínea, Que é identificado a partir da contagem de células de CD4. A gravidade da doença diminui com a adesão à terapêutica $A R V$, e isto é comprovado a partir da contagem menor de células de CD4; no entanto, a troca da medicação, mesmo Que não intencional, torna mais intensa a manifestação da doença $a^{(11)}$.

Conviver com uma doença crônica é lutar contra ela todos os dias e o dia todo, e muitas vezes os portadores e/ou seus cuidadores manifestam a dificuldade Que enfrentam para não se deixar abater:

Acho que o fator que mais dificulta é o emocional, o medo de morrer. Tudo o que ela faz é pensando Que Quer viver, sempre lutando para não cair (Rosa C).

Apesar de serem freqüentes e comuns, os distúrbios de comportamento Que acometem o portador de HIV/Aids, representados por ansiedade, depressão e estresse, muitas vezes são ignorados e não valorizados. Isto só tende a agravar o Quadro, uma vez Que, se o portador não é devidamente tratado em seus aspectos biopsicossociais, essa falta de valorização do sintoma ou transtorno mental faz com Que ele não seja tratado ${ }^{(17)}$.

O psicológico, ele é muito Quieto, Quase não fala. Eu tenho Que mandar, Quando é a consulta, Quando está faltando a medicação e tudo (Laranja C).

Com o passar do tempo o paciente sente a melhora, ainda Que ele tenha problemas com o estigma da doença, pois sabemos Que a Aids é uma doença socialmente estigmatizada, dificultando a Qualidade de vida do portador.

Não conheço sobre o tratamento, e não Quero conhecer; só sei Que Quase morri, e agora preciso tomar esse remédio para não morrer (Branco).

Apega-se à esperança de alcançar a cura por meio da ARV, Que agora tem outro significado: o distanciamento da morte. Mesmo sabendo Que a Aids não tem cura, a terapia ARV tem aumentado a
Qualidade de vida dos portadores do HIV/Aids, aumentando a sobrevida e esperando a cura da síndrome.

\section{CONSIDERAÇÕES FINAIS}

Na realização deste estudo alguns aspectos precisam ser ressaltados, no sentido de despertar nos profissionais da área da saúde, especialmente os da enfermagem, reflexões acerca do cuidado oferecido ao portador de HIV/Aids, de modo particular auuele relacionado à Questão da adesão e não-adesão à terapia antiretroviral. Verificamos Que os atores sociais envolvidos neste estudo revelaram facilidades e dificuldades na adesão aos ARVs. Entre as facilidades relataram a adoção de novas estratégias para a ingestão desses medicamentos, como por exemplo, ingerir com outros alimentos para tornar o gosto agradável. Expressaram ainda Que a ausência de efeitos colaterais dos medicamentos, a pequena Quantidade de medicamentos a serem ingeridos e a presença de memória dos sintomas da doença também colaboram para a adesão, fazendo com Que tentem seguir o tratamento corretamente.

Um aspecto importante observado se refere à rede social dos portadores de HIV/Aids. Quanto aos Que aderiram melhor ao tratamento, verificamos Que tinham uma rede social de suporte mais próxima e Que seus cuidadores manifestaram preocupação em não deixá-los interromper o tratamento, por medo do retorno dos sintomas da doença. Além da família, a religião/espiritualidade foi a rede social Que mais se destacou, e demonstrou ter papel importante na vida do portador de HIV/Aids e sua família, pois a fé e a esperança ajudam a aliviar a dor e o sofrimento.

Quanto às dificuldades de adesão ou à não-adesão à terapia $A R V$, verificamos serem vários os fatores Que contribuem para isto - variando desde o sigilo do diagnóstico até as dificuldades com a ingestão dos medicamentos. Manter o diagnóstico em segredo é um dos fatores Que dificultam a adesão, pois por medo de ser descoberto, o portador deixa de seguir o tratamento (idas ao médico, tomada de medicamentos, busca de medicamentos, entre outros). Nesta mesma direção, contatou-se Que a necessidade de levar o medicamento para o trabalho ocupa papel importante, pois nem sempre é possível utilizar um refrigerador de uso comum sem Que outras pessoas fieuem sabendo do diagnóstico. Os demais fatores referidos como prejudiciais à adesão estão relacionados com a conservação e ingestão dos remédios - conservação em geladeiras, horários, efeitos colaterais, nomes dos medicamentos, uso contínuo e a Quantidade de medicamento a ser ingerida. Verificamos que a irregularidade no horário foi uma prática encontrada com freQüência, o Que desfavorece a adesão.

Sobre o esquema terapêutico é importante destacar Que, embora alguns portadores conheçam os medicamentos integrantes de seu esquema terapêutico, sabendo referir inclusive o nome comercial, o nome da composição e a dosagem utilizada, os portadores e cuidadores, em sua maioria, apesar de demonstrarem familiaridade com os medicamentos, revelaram reconhecê-los de acordo com suas características, tais como o tamanho, a cor, a Quantidade e o número impresso, demonstrando não ter dificuldades nesse aspecto. Contudo, com a possibilidade de troca de laboratório a cada nova licitação para a compra dos medicamentos Que são fornecidos aos portadores revela-se Que este tipo de reconhecimento dos medicamentos também pode comprometer o tratamento. 
Segundo demonstraram ainda os resultados, mesmo aqueles indivíduos Que inicialmente afirmaram tomar corretamente os medicamentos, revelaram mais tarde Que na prática cotidiana não era bem assim. É interessante observar que a polaridade de alguns fatores pode atuar como determinante positivo ou negativo da adesão, dependendo das circunstâncias e do momento em Que eles se manifestem. Sendo assim, o suporte oferecido por profissionais em relação ao tratamento, representado por apoio, informações adecuadas sobre o tratamento e esclarecimentos sobre a gravidade dos efeitos colaterais, pode aumentar a adesão

Por esta razão, julgamos de suma importância Que o portador seja acompanhado na consulta de enfermagem desde o primeiro mês de tratamento, devido à possibilidade de surgir um grande número de reações e efeitos colaterais. Ademais, o acompanhamento do profissional de saúde pode minimizar as conseQüências do impacto da doença e da não-adesão aos medicamentos ARV, pois embora a Aids não tenha cura, a terapia ARV tem propiciado maior longevidade e aumentado a Qualidade de vida dos portadores do HIV/Aids.

\section{REFERÊNCIAS}

I. Sousa AS, Kantorsk LP, Bielemann VLM. A Aids no interior da família: percepção, silêncio e segredo na convivência social. Acta Sci Health Sci 2004; 6(1): 1-9.

2. Gir E, Vaichulonis CG, Oliveira MD. Adesão à terapêutica antiretroviral por indivíduos com HIV/Aids assistidos em uma instituição do interior paulista. Rev Latino-am Enfermagem 2005; 13(5): 634-41

3. Schaurich D, Coelho DF, Motta MGC. A cronicidade no processo saúde-doença repensando a epidemia de Aids após os antiretrovirais. Rev Enferm UERJ 2006; 14(3): 455-62.

4. Ministério da Saúde (BR). Recomendações para terapia antiretroviral em adultos e adolescentes infectados pelo HIV. Brasília: Ministério da Saúde; 2004.

5. Ministério da Saúde (BR). Recomendações para profilaxia da transmissão vertical do HIV e terapia antiretroviral. Brasília (DF); 2007.

6. Bonolo PF, Guimarães MDC. Grupo Atar. Adesão ao tratamento Antiretroviral - ARV em indivíduos infectados pelo HIV em dois serviços públicos de referencia. Belo Horizonte: Universidade Federal de Minas Gerais, Departamento de Medicina Preventiva; 2001.

7. Teixeira PR, Paiva v, Shimma E. Tá difícil de engolir. Experiências de adesão ao tratamento anti-retroviral em São Paulo. São Paulo; 2000. Disponível em: http://bvsms.saude.gov.br/bvs/ publicacoes/ta_dificil.pdf

8. Colombrini MRC, Lopes MHBM, Figueiredo RM. Adesão à terapia antiretroviral para HIV / Aids. Rev Esc Enferm USP 2006; 40 (4): 576-81.

9. Silva ALC. Convivendo com a Aids e seu tratamento: experiência de portadores e familiares [dissertação]. Maringá: Universidade Estadual de Maringá, Departamento de Enfermagem; 2007.

10. Minayo MCS. Fase de análise ou tratamento do material. In: Minayo MCS. O desafio do conhecimento: pesquisa Qualitativa em saúde. $8^{\text {a }}$ ed. São Paulo/Rio de Janeiro: HUCITEC/ ABRASCO, 2004. p. 197-247.

I I. Barroso, LMMB. Adesão ao tratamento com antiretrovirais entre pacientes com Aids. Online Bras I Nurs 2006; 4. Disponível em http://www. uff.br/objnursing/index.php/nursing

12. Goldmeier MK. Dificuldade de adesão à terapia antiretroviral sob o olhar de um profissional de enfermagem. Bol Saúde 2000; 17 (2): 12-29.

13. Simionato MAW, Marcon SS. A construção de sentidos no cotidiano de universitários com deficiência: As dimensões da rede social e do cuidado mental. Psicol Am Lat 2006; 7.

14. Pessini LA. Espiritualidade interpretada pelas ciências e pela saúde. Mundo da Saúde 2007; 3 I (2): I 87- 195.

15. Correa DAM. Religião e saúde: um estudo sobre as representações do fiel carismático sobre os processos de recuperação de enfermidades no grupo de oração da RCC em Maringá, PR. Cienc Cuid Saude 2006; 5( Supl.): 134-I41.

16. Carvalho CML, Martins LFA, Galvão MTG. Mulheres com HIV/ Aids informam conhecimento acerca da infecção. Rev Enferm UERI 2006; 14 (2): 191-5.

17. Waidman MAP, Elsen I. Família e necessidades. Revendo estudos. Acta Sci Health Sci 2004; 6(1): 147-157.

18. Cechin PL. Mulheres com HIV/aids: fragmento de sua face oculta. Rev Bras Enferm 2007; 60(2): 145-9. 